\title{
Dimensional Stones: Weathering Nature and Technical Properties
}

\author{
S. R. Jakhar ${ }^{1}$, Rajendra Mathur ${ }^{2}$ \\ ${ }^{1}$ Department of Geology, J.N.V. University, Jodhpur-342003, India \\ ${ }^{2}$ Department of Chemistry, J.N.V. University, Jodhpur-342003, India
}

\begin{abstract}
Rocks are naturally occurring aggregates of minerals. Most of the rocks are consist of many minerals but some are monomineralic. Rocks which are consist of one or more minerals called stones. Stone is a basic building material used by man from prehistoric time. It is clearly evident by statues and monuments of historic times. Even today stones are used for elegance, beauty, durability and decoration of architectural work in houses, hotels, monuments, temples and palaces. A thorough knowledge of mineral composition, weathering nature, geological and engineering properties and accordingly selection of stone will surely increase life of the rock and the building too. Not only this but the screening among different colour of stones will be good for an area remaining under certain conditions of sunlight and what type of stone should not be used for a kitchen's plate-form. Which stone will be suitable for exterior or interior of a building? The paper is aimed to give an idea of all these characteristics of dimensional stones to common users.
\end{abstract}

Keywords: Dimensional stone, monomineralic, technical properties, weathering, buildings.

\section{Introduction}

With increasing prosperity among citizens of India they want to utilize their money for constructing best quality houses for their comfortable abode. Not only abode they are constructing very beautiful temples and other monuments too. However most of the peoples while selecting dimensional stones for their use, generally they give more preference to attractiveness of the stones colour and texture than to geological and engineering properties. Any rock specially cut or shaped in different sizes are termed as 'Dimensional Stones' for example granite, gabbro, dolerite, sandstone, limestone, marble, serpentinite (commercially known as green marble) gneiss etc. Decorative stones are those utilized for exterior and interior decorations of various high profile buildings. In India the geological time-scale encompasses rocks like granite, marble, sandstone and limestone mostly used in constructing buildings. Rajasthan is especially rich in these building stones and particularly in marbles (Rathore et al. 2000, Roy \& Jakhar, 2002).

Not only modern building but also we have to take care for the heritage buildings from weathering effects. The heritage buildings are buildings that for various factors society have decided that they shall be preserved for periods as long as possible. Heritage buildings are seriously endangered by environmental agencies such as moisture, acid rains, intense solar radiation, temperature, vibrations and prevailing winds which change their physical characteristic. The major effects of environmental agencies include discolouration, abrasion, cracks and fungal growth.

All users of stones are not technical persons hence they are guided here through this paper by giving some ideas about nature and properties of dimensional stones. For example if one wish to use tiles of stone for flooring where peoples allowed walking bare foot only. Then white colour marble or white colour tiles will be suitable because white colour will reflect maximum light back and your floor will remain cool. Green marble (serpentinite) may not be used for exterior decoration because it is highly susceptible to environment and it will get dull by losing its luster very soon. Marble or limestone may not be used for kitchen's plate-form because it is composed of carbonates which react with citric acid of lemons and other acidic materials used in kitchens. Same way marble or limestone should not be used for bathroom tiles because bathrooms remain wet for long time and also washed by chemicals of acidic nature which will start weathering in the marble and limestone.

\section{Weathering}

Weathering is the breakdown and alteration of rocks and minerals at or near the Earth's surface. The extent and style of weathering is mainly controlled by climate. Water is extremely important for weathering. The more water present, the faster weathering occurs. Temperature is also important for weathering. Warmer temperatures also promote faster reactions, so chemical weathering is more effective in warm climates. Thus, warm, humid climates tend to have the most rapid weathering on rocks.

There are three broad categories of mechanisms of weathering: physical, chemical and biological.

Mechanical or Physical Weathering: Mechanical (physical) weathering breaks down stone into smaller fragments without altering or change in their chemical composition. It is process of slow natural disintegration of rocks (Singh, 2008) and also depends on nature of minerals of which the rock is composed. An example of this is fractures in rocks. Temperature variation can cause mechanical weathering. As Minerals expands and contracts with the variation of temperature, freezing and melting cycles can result in cracks and other damage to stones of any building. A list of the following common rock-forming minerals is given to have an idea in order from most resistant to least resistant minerals to physical weathering (i.e. hardest to softest): quartz, orthoclase, muscovite, biotite, plagioclase, olivine, pyroxene, amphibole, calcite 


\section{International Journal of Science and Research (IJSR) \\ ISSN (Online): 2319-7064}

Index Copernicus Value (2013): 6.14 | Impact Factor (2015): 6.391

and dolomite.

Chemical Weathering: Chemical weathering is a process of chemical decomposition of minerals within the rocks by atmospheric gases and moisture. In the presence of atmospheric moisture containing many active gases from atmosphere such as carbon dioxide, oxygen, hydrogen and nitrogen, the chemical change in nature of rocks take place.

Chemical weathering takes place mainly at the surface of rocks and minerals with disappearance of certain minerals and the formation of new materials. This is called chemical transformation, e.g,

Feldspar + water $\rightarrow$ clay mineral + soluble cations and anions

Some of the main processes of chemical weathering involve solution, hydration, hydrolysis, oxidation and reduction, carbonation, base-exchange and formation of colloids.

Solution: Some rocks are composed of one or more minerals that are soluble in water to some extent. The soluble substances are removed by continuous action of water and the rock no longer remains solid and becomes porous, rough and ultimately or decomposes convert into pieces. It is also well known that pure water is not good solvent for minerals in most cases, but when it is acidified by the dissolution of acids for example $\mathrm{NaCl}$, its solvent action for many common minerals is enhanced. Marbles and lime stones mainly contain carbonates (calcite) but they are not easily soluble in pure water but the carbonated water dissolves the rock effectively. Limestone gets decomposed due to chemical weathering.

Carbonation: Rainwater and carbon dioxide in the atmosphere combine to form carbonic acid. This carbonic acid so formed exerts an especially corrosive action over a number of silicate bearing rocks (e.g., Granite) and also on carbonate rocks. It dissolves minerals within the rock, altering the structure and resulting in damage and wear. Removal of cement by acids due to dissolution action, which holds sand particles together in rocks, leads to their disintegration.

Carbonic acid

$$
2 \mathrm{H}_{2} \mathrm{O}+\mathrm{CO}_{2} \rightarrow \mathrm{H}_{2} \mathrm{CO}_{3}
$$

$\mathrm{CaCO}_{3}+\mathrm{H}_{2} \mathrm{CO}_{3} \rightarrow \mathrm{Ca}\left(\mathrm{HCO}_{3}\right)_{2}$

(Calcite, slightly soluble) (Calcium bicarbonate, readily soluble)

Oxidation: The process of addition and combination of oxygen to minerals is termed as oxidation. It is a kind of weathering where oxygen combines with elements in the rock to form oxides. Iron is a chief constituent of many minerals and hence rocks too. In iron-rich rocks oxidation results in a rusting effect similar to the rust found on exposed iron.

$$
4 \mathrm{FeO}+\mathrm{O}_{2} \rightarrow 2 \mathrm{Fe}_{2} \mathrm{O}_{3}
$$

(Ferrous oxide) (Ferric oxide)

Reduction: It is the process of removal of oxygen and it is reverse of oxidation. Brown colour of ferric iron is changed to colour like green, blue and grey due to reduction into ferrous iron. Under the conditions of excess water or water logged condition (less or no oxygen), reduction takes place.

$2 \mathrm{Fe}_{2} \mathrm{O}_{3}-\mathrm{O}_{2} \rightarrow 4 \mathrm{FeO}$
(Hematite) (Ferrous oxide, reduced form)

Hydration: Chemical combination of atmospheric moisture i.e. water with a particular mineral leading to a change in structure. This process of addition of the water molecule is called hydration. Soil forming minerals in rocks do not contain any water and they undergo hydration when exposed to humid conditions. After getting hydration there is swelling and increase in volume of minerals. The minerals lose their luster and become soft.

It is one of the most common processes in nature and works with secondary minerals, like aluminium oxide and iron oxide minerals.

$$
2 \mathrm{Fe}_{2} \mathrm{O}_{3}+3 \mathrm{HOH} \rightarrow 2 \mathrm{Fe}_{2} \mathrm{O}_{3} .3 \mathrm{H}_{2} \mathrm{O}
$$

(Hematite of red colour) (Limonite of yellow colour)

Hydrolysis: It is most important process in chemical weathering. Because of the dissociation of $\mathrm{H}_{2} \mathrm{O}$ into $\mathrm{H}^{+}$and $\mathrm{OH}^{-}$ions which chemically combine with minerals and get changes, such as exchange, decomposition of crystalline structure and formation of new compounds. Water acts as a weak acid on silicate minerals.

$\mathrm{KAl} \mathrm{Si}_{3} \mathrm{O}_{8}+\mathrm{H}^{-} \rightarrow \mathrm{HAlSi}_{3} \mathrm{O}_{8}+\mathrm{K}^{+}$

(Orthoclase) (Ion from water) Silicic acid like structure

(Silt and clay)

Biological Weathering: Biological weathering involves the disintegration of rock and mineral due to the chemical and/or physical agents of an organism. The types of organisms that can cause weathering are plants, animals and man himself. Pressure put forth by growing roots of plants, creeping plants and animal burrowing decays the rocks. Many dead organisms produce organic acids as they decay. These acids increase the solvent power of water. For example, the solubility of silica, alumina and iron is much greater in the presence of organic acids (Bangur, 2013).

Animals burrowing into cracks in the base of heritage or other building can disturb the soil and enlarge the crack. The splitting caused by plant roots can develop cracks in buildings foundation and walls.

\section{Technical Properties of Building Stone}

In order to select the building stone for construction, the properties that are most important and commonly examined are: (i) Mineral composition (ii) Durability and hardness of rocks, (iii) Strength of rocks, (iv) Appearance, (v) Weight, (vi) Fineness of grain and compactness/Texture of rocks, (vii) Porosity and absorption and (viii) Permeability

Mineral Composition: Some minerals alter more quickly than others. Quartz is difficult to dissolve and is hard, so it commonly lasts through both chemical and physical weathering and is the most common mineral in sand. In contrast, minerals like Ca-feldspar and olivine react to form new minerals quickly. They are substantially less common in sediments. Thus, mafic rocks (which contain Ca-feldspar, olivine and pyroxenes) tend to alter to clay minerals very easily and produce little sand and abundant mud. In contrast, granites (quartz, K-feldspar, Na-feldspar, mica) contain 


\section{International Journal of Science and Research (IJSR) \\ ISSN (Online): 2319-7064}

Index Copernicus Value (2013): 6.14 | Impact Factor (2015): 6.391

minerals that react more slowly and tend to produce sandsized grains, especially quartz.

The following list includes minerals from most reactive to least reactive: Calcite, Olivine, Ca-feldspar, Pyroxene, Amphibole, Na-feldspar, Biotite, K-feldspar, Muscovite, Clay Minerals and Quart. If we require a stone for foundation work then quartz dominated rock will be suitable for it because quartz is least susceptible to both chemical and physical weathering. Metamorphic rock like quartzite which is composed of more than $98 \%$ quartz grain will be most suitable for foundation work. More over quartz grains are welded with each other rather than binding of any cementing material.

Durability: Durability or ability to resist the effects of decomposition and of disintegration, such as chemical action (by atmospheric attack, rain water, etc.), heat (especially solar heat in areas where extremes of climate prevail), pressure, etc. would vary according to the degree and manner in rocks are changed by such activities. Durability is one of the most important properties of a building stone and it should always be taken into consideration while purchasing any stone for building construction (Zorlu et al. 2008). It would depend on nature of mineral constituents of the rocks.

In selecting building stones for construction, it would be good to observe the stones at mine site, in order to find out the local effects of the various weathering agents on them. This is necessary since a building stone which may be quite durable in an area having a dry climate, may not be equally durable in another area subject to - periodical wet spells.

Hardness: Hardness of a building stones is dependent on the nature of the rock used and/or nature of minerals of which rocks are made of. Rocks, which are made up of hard resistant minerals like quartz and also having the mineral constituents cemented by a hard siliceous cement, are, naturally more resistant as compared to those, which are composed, mostly of soft minerals like olivine and in which the cementing medium is also friable. That is why, igneous rock like granite is harder as compared to some other types of rocks because there is no cementing material between mineral grains and instead grains are welded with each other. The sedimentary rocks such as fine grained compact sandstones, in which, the sand grains had been cemented by silica, are harder, than those in which the cementing medium is either calcareous or ferruginous.

Strength: The strength of rock is defined as its ability to resist crushing under direct pressure or sometimes resistance to fracture when it is subjected to transverse forces. In actual practice, it had been found, that the building stones usually begin to crack or fracture, at about half their permissible loads and hence it would be necessary to provide for a safety factor of 20, by which term is meant that the building stone proposed to be used, has a crushing strength of at least 20 times the estimated crushing load it would be subjected to. The fresh any dry rocks are naturally stronger than when the same rocks are either altered and/or in a wet state.

Appearance: For construction of buildings, the colour shade of the building stone and its freshness are important. Good looking, attractive and throughout uniform colours such as white, red, off-white, and brick red coloured stones are much in demand.

Weight: As a general rule, the heavier stones have a greater density, lower porosity, and greater degree of compactness. Because of this reason, fine grained heavy and dense rocks are so much preferred for the construction of dams and in harbour works. Closely packed and fine grained igneous rocks are the best for this purpose.

Porosity and absorption: Porosity is nothing but it is the ratio of the pores present between the grains to the total volume of rock and is expressed in percentage. In areas, which are subject to well defined periods of alternate wetting and drying and/or freezing and melting, the degree of porosity and absorption of water possessed by a building stone is of considerable importance, since this tends to affect the durability of the building stone. In cold region in night porous rocks will spelled out and start weakening at edges of buildings. Hence, highly porous dimensional stones are not generally favoured as a constructional material. Similarly, in areas of high rainfall, lime stones would be easily dissolved by percolating water, and buildings built of such stones would be badly affected and will be liable to crumble down.

Permeability: The permeability of a rock defines its ability to transmit a fluid through it. Coarse grained sedimentary rocks are more permeable than fine grained sedimentary and igneous rocks. Less permeability bearing rocks are good for construction work than highly permeability bearing rocks.

BUILDING STONES: The most important building stones are: (i) the granites and its allied rocks, (ii) the sandstones, (iii) the marbles and (iv) the lime stones.

Granite: It is hard durable igneous rocks that form at great depths and pressures under the Earth surface. Granite is resistant to weathering and is found in a variety of pleasing colours viz. pink, red, gray, brown, black etc. (Photo 1). It is capable of retaining its polish fresh as in the original form for a very long time. It is of great strength which can be used with safety for all classes of heavy engineering work and in huge size building construction. The word granite comes from the Latin granum, a grain, in reference to the coarse-grained structure of such a crystalline rock. Granite consists of feldspars, quartz, hornblende, biotite, muscovite and minor accessory minerals such as magnetite, garnet, zircon and apatite. The average mineralogical composition of granite of south India trade is as follows: Feldspar 54\%, quartz $38.8 \%$, biotite $5 \%$ and hypersthene $4.3 \%$ (IBM, 1981).

The important physical properties of granite are as given below (Rathore et al., 2000):

Hardness: $5.8-6.8$

Specific gravity, gm/ $\mathrm{cm}^{3}: 2.6-2.7$

Compressive strength, $\mathrm{Kg} / \mathrm{cm}^{3}: 1000-3000$

Tensile strength, $\mathrm{Kg} / \mathrm{cm}^{2}: 70-250$

Shear strength, $\mathrm{Kg} / \mathrm{cm}^{2}: 140-500$

Modulus of elasticity, $\mathrm{Kg} / \mathrm{cm}^{2}$ x $10^{5}: 2.5$

Coefficient of linear expansion, x $10^{-6:} 4-6$ 


\section{International Journal of Science and Research (IJSR) \\ ISSN (Online): 2319-7064 \\ Index Copernicus Value (2013): 6.14 | Impact Factor (2015): 6.391}

Porosity in \%: $0.5-1.5$

Weight (in lbs per cubic foot): 168.0

Rift and Grain: Direction of easiest splitting.

Due to these qualities it is quite popular for use as tombstones, paving and curbing stones, as architectural material, in the manufacture of tiles, cubes and straight edges. Granite structures can last for over a thousand years. Durability of granite depends to a large extent on the properties of constituent minerals. Some are quite brittle and shatter readily, while others with interlocking grains are very tough. Fine grained granites are harder than coarse grained.

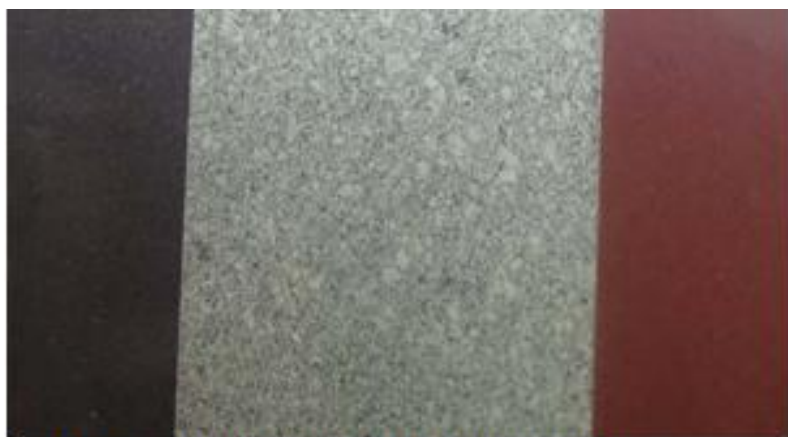

Photo 1: Slabs of Granite in different colours

Sandstone: Sandstone is actually a sedimentary rock formed by the consolidation and compaction of sand-sized grains (2 $\mathrm{mm}$ and $1 / 16 \mathrm{~mm}$, in diameter), consisting predominantly of quartz, held together by natural cement, such as silica, or calcium carbonate, iron oxides or a fine-grained matrix of silt and clay particles. Sometimes the spaces between grains may be empty. Sandstones are commonly gray, buff, red, brown, or yellow, although green and some other colors are also found, which depend in most cases on the nature of the cementing material. For instance, predominance of iron oxide is responsible for red, yellow and brown shades, and that of gluconite for green colour.

As stated above quartz is the most common mineral of sandstone and other minerals like feldspar, garnet, magnetite, tourmaline, mica and zircon etc. may be present in considerable proportions. Similarly, the cementing material is also of various types e.g. siliceous, ferruginous, calcareous and argillaceous etc. The component grains of sandstone show great variation in their shape, size and compaction. The shape and packing (i.e. texture) of the components grains are responsible for the very important properties of porosity and permeability in these rocks.

Physical properties of sandstones are as shown below (Rathore et al, 2000):

Nature : Hard, compact, fine grained, equigranular and homogeneous.

Colour: Brown, cream, pink, green, red etc..

Hardness: $6-6.5$ in Moh's scale

Density: $2.32-2.38 \mathrm{~kg} / \mathrm{m}^{3}$

Specific gravity: 2.57

Water absorption: $1 \%$.

Compressive strength: $36.5 \mathrm{MPa}$

Weight (in lbs per cubic foot): 149.6
Granites which are fine grained, compact and free from joints and fractures are relatively speaking, more resistant to weathering as compared to other rock types. The texture of granite signifies the grain size and the arrangement of mineral constituents. Granites with uniform distribution of minerals and uniform grain size are in commercial demand for building and ornamental uses. Weathering effect may also be considered to avoid shade variations. It generally happens in case of feldspar which is responsible in deciding colour of the granite as it sometime covers $50 \%$ of the total volume.

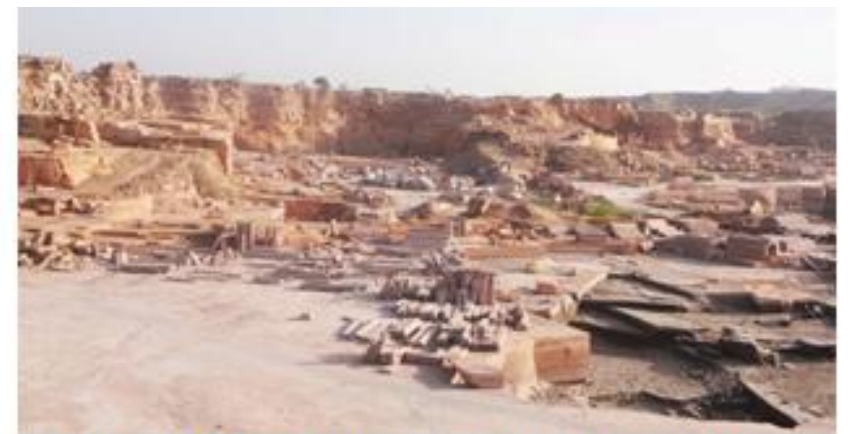

Photo 2: Sandstone mine at Jodhpur and textures.

Sandstone has variety of uses such as roofing, flooring, paving, paneling, beams, pillars, doors and window-sills, wall facings, fence-posts, milestone etc. It is also suitable for carving and making perforated windows and jallis. This sandstone is being quarried (Photo 2) and used from centuries and number of historical buildings and monuments such as Red Fort of Delhi, Parliament House and National Museum, Agra, Bharatpur and Jodhpur Forts, etc. are made of this stone.

Marble: The marble is crystalline, compact variety of metamorphosed limestone in which the carbonates (calcite) have recrystallized into a dense form which takes good polish and is used as a decorative and building stone. The word "marble" derives from the Greek marmaros, "shining stone". This is also the basis for the English word "marmoreal" meaning "marble-like"

Commercially, the term marble is extended to include any rock composed of calcium carbonate that takes a polish, available in blockable sizes and also includes some ordinary limestone. But in strict sense marble is a rock composed of calcite (> 95\%), a crystalline form of calcium carbonate. Texturally fine grained marbles are of good quality than to medium and coarse grained ones. Marble is not different from limestone chemically. Its primary difference will be that it does not contain porosity as limestone does.

Pure white marble is the result of metamorphism of very pure limestones. The characteristic swirls and veins of many coloured marble varieties are usually due to various mineral impurities such as clay, silt, sand, iron oxides, or chert which were originally present as grains or layers in the limestone. These various impurities have been mobilized and recrystallized by the intense pressure and heat of the metamorphism (DMG, 2000). 


\section{International Journal of Science and Research (IJSR) \\ ISSN (Online): 2319-7064}

Index Copernicus Value (2013): 6.14 | Impact Factor (2015): 6.391

Physical properties of marble are as shown below (Rathore et al, 2000):

Colour: White, pink, green, black etc. Striped and shade of different colours also.

Form: Crystalline and non-crystalline (coarse, medium and fine grained)

Luster: Glassy

Reflectivity: $80-95 \%$

Hardness: 2.8 to 3.5

Specific gravity: 2.70 to 2.90

Porosity (void ratio): 0.0002 to $0.5 \%$

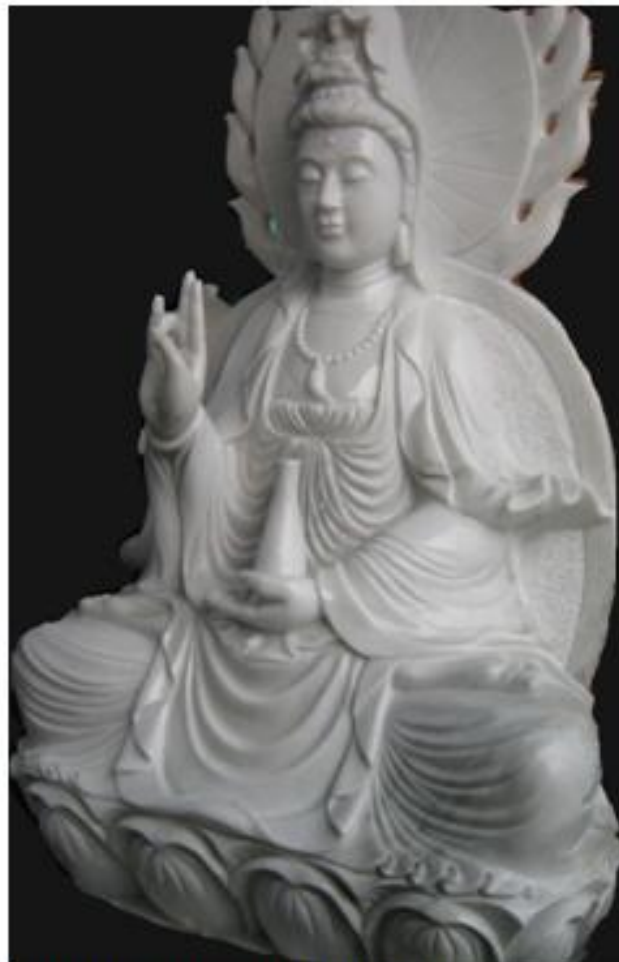

Photo 3: Statue carved in Marble.
Abrasive resistance: Abrasive hardness ranges from 8 to 42 . Solubility: Varies in calcite type to dolomitic, soluble residue negligible

Porosity: Volume \% of pore space in marble (0.002 to 0.5 )

Absorption: Amount of liquid absorbed on immersion is negligible.

Strength: Measure of its capacity to resist and stress. Depends upon rift, hardness of grains, state of aggregation, degree of cohesion and interlocking of grains (56 - 190 $\mathrm{MPa})$

\section{Limestone}

The term limestone is applied to any sedimentary rock consisting essentially of carbonates. The two most important constituents are calcite and dolomite. In common limestones impurities like clays, feldspars, quartz and pyrite may be present in considerable amounts. Theoretically, it contains $56 \%$ lime and $44 \%$ carbon dioxide. In some limestones, the magnesium carbonate (dolomite) predominates and the rock is then termed dolomite. Carbonates are in the form of calcite, aragonite and dolomite, since aragonite is more easily dissolved or converted to calcite, it is absent in ancient limestones.

Limestones exhibit a great variety of textures and structures. These rocks may be compact or loosely packed, hard or soft and may show clastic, concretionary or organic structures. Limestone is sometimes termed as flag-stone in the building industry. A limestone rock which separates well along the stratification into a few centimeters thick (normally $5 \mathrm{~cm}$.) slabs used for roofing and paving is termed flagstone. The lime stone weather faster than the marble.

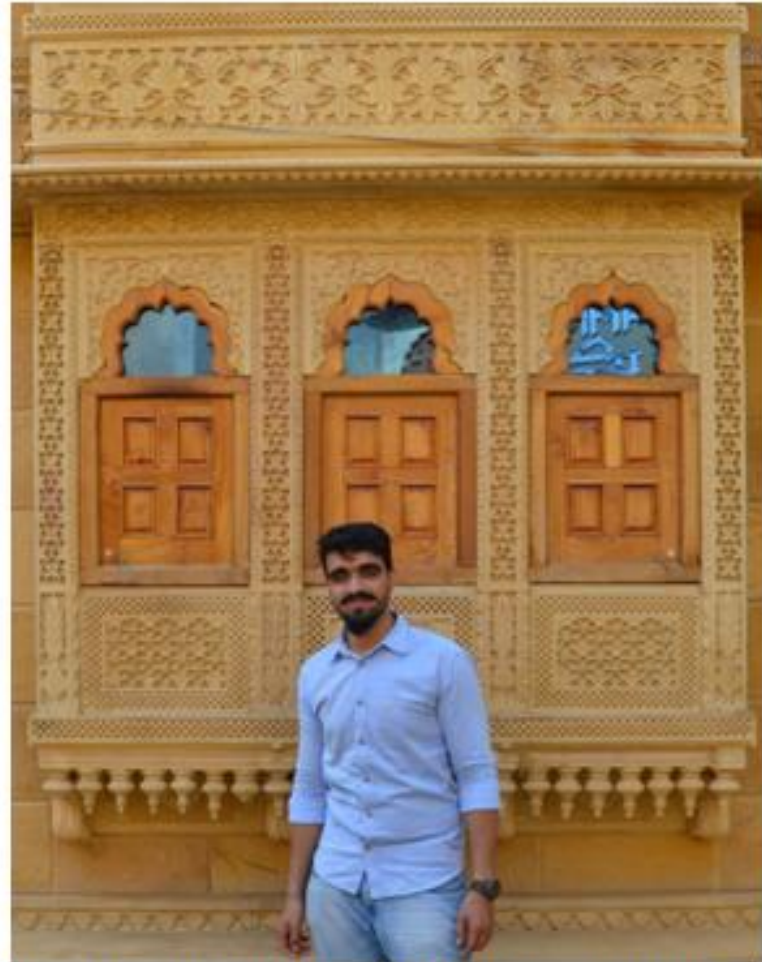

Photo 4: Beautiful carving in Yellow Limestone of Jaisalmer

Physical properties of limestone are as given below (Rathore et al, 2000):

Colour: Greenish blue and brown, also cream and black.

Form: Massive, fine grained, 10 - 52 micron or lesser.

Hardness: 2.5 to 3.5

Specific gravity: 2.70 to 2.90

Porosity (void ratio): 0.0002 to $0.5 \%$

Abrasive Index: 8 to 42 .

Water absorption: $0.14-0.47 \%$

Weight in lbs per cubic foot 168.0

\section{Conclusions}

The article will be useful to dimensional and decorative stone producers, stone users, architects, archeologist, geologist, structural engineers and those who are directly or indirectly involved in the stone industry. While purchasing a stone one must give preference to weathering resistant minerals, climatic conditions, small grain size, mutual grain packing, colours of beautiful and uniform look, and need based stones quality. Stones may also be selected not only according to their weathering nature and technical properties but also preferences to place of their use in building is 


\section{International Journal of Science and Research (IJSR) \\ ISSN (Online): 2319-7064 \\ Index Copernicus Value (2013): 6.14 | Impact Factor (2015): 6.391}

equally important, such as it will be used for foundation, wall erection, flooring, roofing, interior or exterior places.

\section{References}

[1] Alexandrowicz Z. 2009. Sandstone rocks on tourist trails of the Carpathian Foothill. Geological and landscape aspects and their threats. Wierchy. 75:179198.

[2] Alexandrowicz Z, Pawlikowski M. 1982. Mineral crusts of the surface weathering zone of sandstone tors in the Polish Carpathians. Mineral Pol.; 13(2):41-59.

[3] Bai Y, Thompson GE, Martinez-Ramirez S, Brüeggerhoff S. 2003. Mineralogical study of salt crusts formed on historic building stones. Sci Tot Environ. 302(1-3):247-251.

[4] Bromowicz J, Magiera J. 2010. Geological investigations of stone work of early mediaeval buildings in Kraków. Biul Państw Inst Geol. 439:425436.

[5] DMG, 1998. Rajasthan Mineral Bulletin, no. 2-3, pp. 13-17.

[6] DMG, 2000. Rajasthan Mineral Bulletin vol.21, No.4, pp 21-30.

[7] IBM, 1981. Granite, a market survey. Indian Bureau of Mines, Nagpur.

[8] Jain O.P. and Banthia H.R., 2003. Sandstones of Rajasthan-Some Views. Sandstone Spectrum 2003. Department of Mines and Geology, vol.2, 01-09pp.

[9] Mariola Marszałek, Zofia Alexandrowicz, and Grzegorz Rzepa, 2014. Composition of weathering crusts on sandstones from natural outcrops and architectonic elements in an urban environment. Environ Sci Pollut Res Int. 21: 14023-14036. Published online 2014 Jul 20. doi: 10.1007/s11356-014-3312-y

[10] Maldonado L., Veleva L. and Diaz Ballote L. 2011. Characterization of limestone for building in the Yucatan, Peninsula, Mexico. Applied Physics A, 103: 1105-1110. DOI 10.1007/s0039-010-6049-6

[11] Rathore, S.S., Bhardwas G.S. and Jain S.C., 2000. Dimensional Stone Technology. Himanshu Publications, Udaipur, 283p.

[12] Reddy D.V., 1996. Decorative and Dimensional stones of India. CBS Publishers and Distributors, New delhi, $276 \mathrm{p}$.

[13] Thiagrajan R., 1976. Natural Building Stones and Architecture in India. Indian Minerals, vol. 30(4), 56$62 \mathrm{pp}$.

[14] Tugrul A., Zarif I.H. (1998). "The influence of mineralogical Textural and chemical characteristics on the durability of selected sandstones in Istanbul, Turkey.' Bull Eng. Geol. Env 57: 185-190.

[15] Ulusay R, Türeli K, Ider MH (1994) Prediction of engineering properties of a selected litharenite sandstone from its petrographic characteristics using correlation and multivariate statistical techniques. Eng Geol 37: 135-157.

[16]Zorlu, K., Ulusay, R., Ocakoglu, F., Gokceoglu, C., Sonmez, H., 2004. Predicting intact rock properties of selected sandstone using petrographic thin-section data. International Journal of Rock Mechanics and mining Sciences 41(1), 93-98.
[17]Zorlu K., Gokceoglu C., Ocakaglu F., Nefesioglu H.A., Acikalin S. 2008. "Prediction of uniaxial compressive strength of sandstone using petrography based models.' 'Engineering Geology 96:141-158. 